dilectures » (Rimbaud et Verlaine, bien sûr mais aussi Auden et Henri Thomas), ou la peinture avec une conversation suivie sur neuf poèmes avec Félicien Rops ou encore avec une réflexion poétique à partir d'un tableau de Bruegel, Paysage avec la chute d'Icare. On sait que dans ce tableau, la chute d'Icare est placée en arrière plan d'un paysan et son araire. Icare représente le rêve de l'enfance, il est le prétexte à une réflexion sur le monde des adultes qui se termine par une note pessimiste: «nous ne sommes plus qu'une trace déjà/ dans la nuit, la retombée d'un songe// entre les rails du présent, et qui s'efface ». Cette conclusion sonne dans tout le livre de façon identique. Le poète dit son mal de vivre dans le temps, mais aussi dans la société : « je prie que la terre/ se renverse en un sursaut de honte// et de colère à la face des puissants... » Le rêve, l'idéal, ont encore des forces cachées dans l'âme de l'enfant qu'est toujours un peu le poète. C'est ce qui lui permet de toujours trouver les mots pour la révolte.

Au total voilà un recueil riche de sentiments, de vigueur dans l'écriture, malgré le ton désanchanté de l'homme.

Bernard Fournier

Guillevic. Art poétique, précédé de Paroi, suivi de Le Chant, Préface de Serge Gaubert. Poésie/ Gallimard, 2001.

O uatre ans après sa dispariton on retrouve Guillevic chez Gallimard, et on redécouvre combien sa poésie est limpide, vraie et juste, humaine. L'éditeur lui consacre un quatrième volume dans sa célèbre collection Poésie, mettant ainsi la moitié de l'oeuvre en collection de poche. L'édition ajoute à Art poétique (1989), et à son pendant que constitue Le Chant (1990), le poème Paroi (1970), auquel on ne s'attendait pas. C'est là une heureuse surprise. Elle redonne à Guillevic une image un peu différente de celle à laquelle on s'était habitué. Paroi, s'avance dans des terres apparamment éloignées du breton matérialiste de Terraqué. Et avance dans une forme de poésie qu'on pourrait appeler philosophique.

S'il y a des traces de discours dans ce poème, elles s'élèvent au niveau de la poésie. L'incipit en est révélateur : " Je dois te dire,/ Bien qu'il m'en coûte/ Que tu saches:// Quand je suis seul,/ Je parle. " D'emblee, un dialogue s'instaure sur le ton familier de la confidence. Le poète propose une ouverture plus large quand il se sent enfermé dans ses propres manières de penser : "Il y a donc/ A découvrir. » C'est pourquoi, a contrario le verbe tend parfois à la définition, forme recluse : « Essayer/ D'être la question/Qui s'accepte indemne de réponse. » Le texte tourne autour de la problématique de la question. En l'occurrence, ici, la « paroi ».

Ce thème n'est pas éloigné des «Murs » de Terraqué, ou même des « Rocs », fermés sur euxmêmes, « paroi de roc », comme le définit bien Serge Gaubert dans sa préface. L'auteur pense aussi au «mur [...] les lamentations », et à la paroi «barbelée. Electrifiée». La paroi est une occultation intérieure qu'il s'agit d'éclairer. Guillevic rejette l'idée de Dieu que la «paroi » aurait pu fait naître. Récemment Michel de Maulne (dans un entretien avec Bernard Mazo, in Aujourd'hui poème, $\mathrm{n}^{\circ} 19$, mars 2001), rendait compte des derniers moments de Guillevic « en profondeur, vraiment dans une sorte de méditation profonde d'ordre mystique. » Le poète avoue sa difficulté quand il affronte «ce qui en [lui] est paroi »: "Facile à dire,/ Facile à se promettre.// Mais vivre me parjure. ». Il termine par un infinitif qui dit l'ouverture: « Rêver le temps/ Devenu corps».

\title{
LittéRéalité 124
}


"De Paroi au Chant se dessine un parcours », note Serge Gaubert. Art poétique n'a rien d'une leçon d'écriture. Loin d'être didactique, en effet, ce poème se veut une réflexion dans le prolongement d'Inclus, en 1973. L'incipit reprend les mots mêmes par lesquels Paroi finit, l'être et le temps: «Si je n'écris pas ce matin,/ Je n'en saurais pas davantage,// Je ne saurai rien/ De ce que je peux être » Le poète n'existe que par l'écriture. Le temps, particulièrement sensible chez un homme de quatre-vingts ans, revêt une importance primordiale. Dans le même moment, Guillevic fait preuve d'une force de création peu commune à cet âge. Le poète combat les forces obscures qui agissent en lui, «Les mots sont des épées/ Contre les ventres de brouillards ». Le poème devient joie: «Un rythme s'y met/ Et tu acquiers un bien. », obstacle au temps et gère l'espace cosmique. « Avec des mots/ Et leurs souvenirs/Faire un noyau/Que l'on puisse, ou presque,/ Tenir dans la main,// Un noyau de temps. », « Le poème/ Ne tue pas le vide,/ Il l'eloigne. ». Le poète " sai[t] recueillir ", parce qu'il se met au centre de sa sphère, non dans un nouvel humanisme égocentrique, mais dans une attitude qui doit beaucoup à l'humilité d'un être proche de la terre.

Le Chant peut déconcerter tant il semble proche d'Art poétique. Il en présente le versant lyrique. «Le chant institue une relation, la crée sans la commenter ni la décrire» dit fort justement Serge Gaubert. Dans ce type de poème à l'inspiration brève, Guillevic savoure son bonheur. On y sent un apaisement. Entre le silence et le chant, le poète aborde une certaine mystique, une approche de l'espace du sacré, qui est en même temps une approche de son être le plus profond. «Qui entend le chant/ Se dit: j'existe,// Je crois que je suis/ Sans plus de limites. » Les rapports entre l'être et le temps se trouvent, dans le poème, comme rassérénés pour donner à l'homme une impression de toute puissance, mais infime, toute intérieure, et, de surcroît évanescente. «Tout se chante, à son heure, à sa façon ». Le chant peut être considéré comme une acceptation, chez ce poète d'abord tourné vers les objets, d'un lyrisme original. Mais sans épanchement. Il s'agit de rendre compte de l'ici et maintenant par une voix qui se module sur tous les tons, allant du pathétique à l'humour, en passant par le ton grave de la méditation: «Tous les chants/ Ne sont pas de triomphe », «Par temps sec/Le chant des vers de terre », «Le grillon de mon enfance ». Le livre se termine par une réflexion mallarméenne: « La feuille blanche/ Ne réussit le chant//Que par le silence/Qu'on lui impose ». Mais au lieu de clore son expérience par un échec. Guillevic, en toute vitalité, compose avec le silence pour faire remonter la voix quintessenciée. C'est alors qu'il peut dire au lecteur: "C'est quand tu chantes pour toi/ Que tu ouvres pour les autres/ L'espace qu'ils désirent ».

\section{Bernard Fournier, Noailles (France)}

Guillevic. Proses ou Boire dans le secret des grottes. Fischbacher, ev. 2001.

C ette jolie petite édition nous donne à lire pour la premère fois des textes en prose de fuillevic. Nous découvrons ainsi que le poète a pu osciller sur des formes diverses avant de choisir définitivement le vers libre court. Ces proses tiennent à la fois de Nerval et de Michaux. On y perçoit une attention à soi, à son propre monde intérieur, aux labyrinthes de la psychologie. Le texte a parfois l'allure d'une saynète, tel «Le Roi» ou «Le boufon du roi », dans lesquels le poète refléchit sur «le cafard » comme état d'âme, ou les grimaces que se fabrique ce double du roi. «Caün» offre une profonde méditation sur l'origine de la culpabilité. «On ne t'a pas assez tué», dit-il 